\title{
Analysis of Serum 25- (OH) D Levels status in Subjects Suffering from Pulmonary Tuberculosis: A Teaching Hospital Based study in Western Uttar Pradesh Region
}

\author{
Shailendra Kumar Jain ${ }^{1}$ \\ ${ }^{1}$ Assistant Professor, Department of pulmonary medicine, Govt. Medical College Budaun, Uttar Pradesh, India.
}

\section{Abstract}

Background: This report analyses the outcomes of a case control investigation shelled in an eventual legion learning of domestic contamination (HHCs) of TB patients. Further, these data was pooled with other available probable learning of status of vitamin D and TB hazard to demeanor asingle-participant data (IPD). Subjects and Methods: In the study recently diagnosed pulmonary tuberculosis patients were involved with a total number of 28 with a male female ration of $18: 10$ and on the other side 28 healthy controls were selected with a male female ratio of 16:12 according to inclusion and elimination criterion through non-probability purposive sampling. Results: The mean age of cases with tuberculosis was 38.8 \pm 7.5 years whereas the represent age of controls was $36 \pm 5.04$ years. Remarkable differences were observed between the patients with tuberculosis and controls. The differences were very significant in RBC counts, Hemoglobin,and Platelet counts. Squat standard hemoglobin values were found in the majority of study subjects in common and specifically in patients with pulmonary tuberculosis. Conclusion: It has been found in the study that squat serum $25-(\mathrm{OH}) \mathrm{D}$ levels were related through amplified threat of future succession to TB disease in a dose-depending method.

Keywords: serum 25- (OH) D, Pulmonary Tuberculosis, Vitamin D.

Corresponding Author: Dr. Shailendra Kumar Jain, Assistant Professor, Department of pulmonary medicine, Govt. Medical College Budaun, Uttar Pradesh, India.

Received: December 2019

Accepted: January 2020

\section{Introduction}

Rapid progression in diagnostic technology and innovations of new antituberculous drugs seem perhaps not enough to avert TB as it still persists a key threat to public health. The World Health Assembly in May 2014, at Geneva sanctioned "The End TB Strategy" with an objective to finish the worldwide epidemic of TB by 2035 with objectives to diminish TB mortalities by $95 \%$ and lessen the novel emerging cases by $90 \%$ along with an assurance that no family is fraught with shattering expenditure caused by TB. Sadly, India alone adds to a quarter of TB encumber worldwide. The figures provided by WHO statistics for 2015 are very alarming as it bestows an anticipated frequency and pervasiveness of 2.2 and 2.5 million correspondingly for TB in India. ${ }^{[1]} \mathrm{TB}$ accompanied with HIV is as one of the foremost reasons of morbidity and transience among common residents.

Paucity in vitamin D is a major cause in TB patients. Patients having a vitamin D scarcity possess drastically advanced jeopardy of mounting lively TB as in comparison made with those who were found with standard vitamin D levels. ${ }^{[2-4]}$ This has been predominantly experimental in emigrants approaching to the UK from Asia. ${ }^{[5]}$ Minor serum levels of vitamin $\mathrm{D}$ is a exceptionally general finding in patients with TB as compared with normal controls.${ }^{6,7}$ Studies propose that vitamin D supplementation during treatment chiefly in under privileged population might improvise the results in anti-TB treatment. Other studies, on the other hand, have revealed no enhanced healing action with regards to sputum culture adaptation and ultimate cure upshots between patients getting and those devoid of supplementation of vitamin $\mathrm{D}^{[5,8]}$. The dissimilar findings pave way to the discussion in case vitamin D insufficiency is uniformly dispersed amongst patients diagnosed with diverse categories of patients with TB or TB patients with added contemporaneous co morbidities like diabetes mellitus (DM).Generally, granuloma holds the TB infection, and the disease may lingerquiescent, or embryonic, for years. Nevertheless, resistant dearth derivative to an occurrence such as coinfection with HIV or undernourishment, can escort to foundation of the disease. ${ }^{[9]}$ Vitamin $\mathrm{D}$ is expected to have a significant function in macrophage launch and the consequent constraint of MTB expansion. ${ }^{[10]}$ Developing countries have been found to possess Low levels of Vitamin D .Though the variations depend on the food reinforcement course of action, demographic skin texture, geographic setting and weather. Vitamin D scarcity has been drawn in as a threat for tuberculosis. ${ }^{[11]}$ Vitamin D displays a vital part towards numerous malignancies. Vitamin D deficit may 
lead to the illnesses like hypertension, diabetes, autoimmune disorders, contagion and cancer. ${ }^{[12]}$ It amends gene appearance in the tissues where it functions by fastening to explicit receptor. Vitamin D binding receptors have several known actions that we are unaware of. ${ }^{[13,14]}$ Researches on the function of vitamin D in TB have been executed very less in Asian populace .The connection of vitamin $\mathrm{D}$ status on the menace of $\mathrm{TB}$ succession has been discussed here in two ways. This report analyses the outcomes of a case control investigation shelled in an eventual legion learning of domestic contamination (HHCs) of TB patients. Further, these data was pooled with other available probable learning of status of vitamin $D$ and $T B$ hazard to demeanor a single-participant data (IPD).

\section{Subjects and Methods}

This study was carried out in the department of pulmonary medicine, Govt. Medical College Budaun, Uttar Pradesh during the period from September 2017 to December 2019. In the study recently diagnosed pulmonary tuberculosis patients were involved with a total number of 28 with a male female ration of $18: 10$ and on the other side 28 healthy controls were selected with a male female ratio of 16:12 according to inclusion and elimination criterion through non-probability purposive sampling.

For exclusion criteria, patients with lately identified treatment immature pulmonary TB with positive sputum on two early morning samples or else patients with either type 2 diabetes or both the disorders together were monitored. The family members were the healthy controls of the patients. The diabetic examination was performed under American diabetes association criteria or else by the precedent records. The exclusion category was kept huge with a variety to ensure the accuracy of findings. The exclusion was made of the patients who with drug resistant TB or extra pulmonary TB, patients with momentous renal, cardiac illness or respiratory ailment other than TB, pregnant, lactating others, and seriously ill patients. Drugs interfering with vitamin D metabolism which contains alcohol, vitamin supplements, calcium preparations or steroids were too excluded from the study. The study protocol was permitted by the ethics group. All patients supplied a nin formed written sanction for contribution in this study.

\section{Biochemical Analysis}

An overnight rapid $5 \mathrm{ml}$ of venous blood samples were collected for $25(\mathrm{OH})$ D3 levels. The venous blood was collected in plastic serum tubes. Ice boxes were used for sampling and sent instantly to laboratory. Serum was alienated by centrifugation and $25(\mathrm{OH})$ D3 levels precised using chemilum in essence using Roche diagnosis Elesys. All the findings were suitable established by pathologist. A patient having level of vitamin D less than $25 \mathrm{ng} / \mathrm{ml}$ was observed to be Vitamin D scarce for study.
In study, all values were articulated as mean \pm S.D. Data was evaluated on SPSS version. Eighteen unremitting along with resounding variables were examined by student's investigation and chi square test correspondingly. The noteworthy $\mathrm{p}$ - value was considered at $\leq 0.05$.

\section{Results}

[Table-1] depicts the medical and demographic distinctiveness of population studied. Selected samples with tuberculosis were twenty eight in number comprising sixteen male an twelve female and on the other side there were and 28 patients as control including eighteen male and ten female. The mean age of cases with tuberculosis was $38.8 \pm 7.5$ years whereas the represent age of controlswas $36 \pm 5.04$ years. The table also indicates smoking habit, obesity, BMI, gender distribution, and chest $\mathrm{x}$ ray showing cavitations. Remarkable differences were observed between the patients with tuberculosis and controls. The differences were very significant in RBC counts, Hemoglobin, and Platelet counts. Squat standard hemoglobin values were found in the majority of study subjects in common and specifically in patients with pulmonary tuberculosis. Serum alkaline phosphatase too reflected noteworthy divergence as shown in [Table-1].

Table 1: Clinical and Demographic characteristics of study
group
\begin{tabular}{|l|l|l|}
\hline Variables & Study Group & Control \\
\hline Age in Years & $38.8 \pm 7.5$ & $36 \pm 5.04 *$ \\
\hline Male & $16(57.1 \%)$ & $18(64.2 \%)^{*}$ \\
\hline Female & $12(42.8 \%)$ & $10(35.7 \%)^{*}$ \\
\hline Obesity & $36 \%$ & $42 \%$ \\
\hline BMI $(\mathrm{kg} / \mathrm{m} 2)$ & $27.03 \pm 4.05$ & $26.01 \pm 3.8^{*}$ \\
\hline Smokers & $48.8 \%$ & $22 \%$ \\
\hline Chest X-ray cavity & $11(39.2 \%)$ & - \\
\hline Hemoglobin $(\mathrm{gm} / \mathrm{dl})$ & $12 \pm 3.5$ & $14 \pm 4.3$ \\
\hline RBC counts $(\mathrm{x} 109 \mu \mathrm{l}-1)$ & $4.9 \pm 2.3$ & $5.5 \pm 2.8$ \\
\hline WBC counts $(\mu \mathrm{l}-1)$ & $7392 \pm 171.3$ & $7079 \pm 156.4$ \\
\hline Platelets $(\mathrm{x} 109 \mu 1-1)$ & $4.8 \pm 2.9$ & $4.5 \pm 3.9$ \\
\hline ESR & $50 \pm 20.5$ & $7.4 \pm 4.1$ \\
\hline Alkaline phosphatase(iu) & $107.8 \pm 15.8$ & $98.8 \pm 11.4$ \\
\hline $\begin{array}{l}\text { Vitamin D3 (ng/ml) } \\
\text { Mean } \pm \text { SD) }\end{array}$ & $23.4 \pm 11.5$ & $31.49 \pm 13.58$ \\
\hline $\begin{array}{l}\text { Vitamin D3 deficiency } \\
\text { [n(\%)] }\end{array}$ & $18(64.2 \%)$ & $10(35.7 \%)$ \\
\hline
\end{tabular}

The clinical distinctiveness of patients with pulmonary tuberculosis has been displayed in table 2. Seventeen patients were observed to have Vitamin D scarce and eleven patients had usual levels.

Table 2: Clinical characteristics of patients with pulmonary tuberculosis

\begin{tabular}{|l|l|l|}
\hline \multirow{2}{*}{ Variables } & Vitamin D Levels \\
\cline { 2 - 3 } & $\begin{array}{l}\text { Deficient } \\
<25 \mathrm{ng} / \mathrm{ml}\end{array}$ & $\begin{array}{l}\text { Normal } \\
>25 \mathrm{ng} / \mathrm{ml}\end{array}$ \\
\hline Number of patients & $17(60.7 \%)$ & $11(39.2 \%)$ \\
\hline BMI $(\mathrm{kg} / \mathrm{m} 2)$ & $21.03 \pm 7.54$ & $24.8 \pm 5.4$ \\
\hline Vitamin D3(ng/ml) & $18.23 \pm 5.3$ & $28.4 \pm 6.15$ \\
\hline
\end{tabular}

\section{Statistical Analysis}




\section{Discussion}

Vitamin D has been observed a major cause in augmented menace of tuberculosis in varied populace ${ }^{[15,16]}$ Vitamin $\mathrm{D}$ has a very crucial role to play in macrophage commencement and constraint of mycobacterial development. A number of biological studies found upshots of Vitamin D on resistant organization of the body. Studies reflect that Vitamin $D$ has anultimate function in containment of propagation of Mycobacterium tuberculosis and inclusive provocative retort formed derivative toit. ${ }^{[17,18]}$ Likewise, on activating of toll-like receptors by molecules of the tubercle bacillus, the structure of microbe-killing cathelicid in is weakened in the nonappearance of ample serum Vitamin D. ${ }^{[19]}$ Nonetheless, the in-vivo involvement amid Vitamin D standing and tuberculosis is still a arguable concern. It was observed in the study that that Vitamin $\mathrm{D}$ dearth, as evaluated by 25 (OHD) level, was elevated in patients with tuberculosis in both the genders. In order to get fine results, only those of tuberculosis patients were incorporated who were yet to begincure as anti tuberculosis chemotherapy can lessen serum Vitamin D levels. The probable alliance amid Vitamin D and tuberculosis was first accounted approx 20 years ago, ${ }^{[20]}$ although succeeding researches have acquiesced in congruous results.

The occurrence of vitamin D dearth is very elevated in Indian inhabitants as exposed by a variety of studies. Several studies have displayed that $96 \%$ of neonates in North India, ${ }^{[21]} 91 \%$ of hale and hearty school girls, ${ }^{[22]} 78 \%$ of vigorous hospital staff and $^{23} 84 \%$ of expecting woman34were observed to keep hypo vitamin osisusing criteria of crucial $25(\mathrm{OH})$ vitamin D scarce as serum level underneath $20 \mathrm{ng} / \mathrm{ml}{ }^{[25,26]}$

Serum absorption of $25-\mathrm{OH}$ vitamin $\mathrm{D}$ in patients having TB are usually poorer than in vigorous harmonized controls and the pervasiveness of TB is advanced amongst those with squat serum 25-OH vitamin $\mathrm{D}$ absorption such as mature subjects and as immigrant to the UK. ${ }^{[26]}$ Frequency of pulmonary TB is 2-3 advanced in diabetic patients. ${ }^{[27]}$ It can be attribute to vitamin $\mathrm{D}$ shortage. There is fine number of confirmation to propose that lack in serum vitamin D levels conciliation cell mediated resistance and adds to establishment of latent TB. ${ }^{[28]}$

\section{Conclusion}

It has been found in the study that squatserum $25-(\mathrm{OH}) \mathrm{D}$ levels were related through amplified threat of future succession to TB disease in a dose-depending method. Vitamin D inference cannot be done every patient, however supplement vitamin D can be given in those who are at elevated peril of possessing vitamin $\mathrm{D}$ deficit. This practice could be of some therapeutic advantage with regards to ailment of TB and even glycemic check.
References

1. Global Tuberculosis Control 2015, WHO, Geneva,2015.

2. Zittermann A. Vitamin D in preventive medicine: are we ignoring theevidence? Br J Nutr2003;89:552-72.

3. Zeng J, Wu G, Yang W, et al. A serum vitamin D level. Plos One2015.

4. Arnedo-Pena A, Juan-CerdánJV, Romeu-García A, et al. Vitamin D status and incidence of tuberculosis among contacts of pulmonary tuberculosis patients. Int J TubercLung Dis2015;19:65-9.

5. Davies PD, Martineau AR. Vitamin D and tuberculosis: more effectivein prevention than treatment? Int $\mathrm{J}$ TubercLung Dis2015;19:876-7.

6. Zhan Y, Jiang L. Status of vitamin D, antimicrobial peptide cathelicidin and $\mathrm{T}$ helper-associated cytokines in patients with diabetes mellitus and pulmonary tuberculosis. ExpTher Med2015;9:11-16.

7. Wang Q, Ma A, Bygbjerg IC, et al. Rationale and design of a randomized controlled trial of the effect of retinol and vitamin D supplementation on treatment in active pulmonary tuberculosis patients with diabetes. BMC Infect Dis 2013;13:104-21 http://www.biomedcentral.com/1471-2334/13/104.

8. Sloan DJ, Mwandumba HC, Kamdolozi M, et al. Vitamin D deficiency in Malawian adults with pulmonary tuberculosis: risk factors and treatment outcomes. Int J TubercLung Dis2015;19:90411.

9. Russell DG. Mycobacterium tuberculosis: here today, and heretomorrow. Nat Rev MolCellBiol. 2001;2:569-577.

10. Chandra G, SelvarajP, JawaharM, BanurekhaV, NarayananP. Effect of Vitamin D3 on phagocytic potential of macrophages with live Mycobacterium tuberculosis and lympho-proliferative response in pulmonary tuberculosis. J ClinImmunol 2004; 24: 249-57.

11. Chan T. Vitamin D deficiency and susceptibility to tuberculosis. CalcifTissue Int2000;66:476-8.

12. Stechschulte SA, Kirsner RS, Federman DG. Vitamin D: Bone and Beyond, Rationale and Recommendations for Supplementation. Am J Med 2009;122(9):793-802.

13. Denis M. Killing of Mycobacterium Tuberculosis within human monocytes, Activation by cytokines and Calcitriol. Clin ExpImmuno 11991;84:200-6..

14. Abu-AmerY, Bar-Shavit Z. Impaired bone marrow derived macrophage differentiation in vitamin $D$ deficiency. Cell Immunol1993;151(2):356-68.

15. GibneyKB, MacGregorL, Leder K, et al. Vitamin D deficiency is associatedwith tuberculosis and latent tuberculosis infection in immigrants from sub-Saharan Africa. ClinInfectDis.2008;46:443446.

16. Williams B, Williams AJ, Anderson ST. Vitamin D deficiency and insufficiency in children with tuberculosis. Pediatr Infect Dis J.2008;27:941-942.

17. Liu PT, StengerS, Tang DH, Modlin RL. Cutting edge: Vitamin D mediated human antimicrobial activity against Mycobacterium tuberculosis is dependent on the induction of cathelicidin. J Immunol2007;179:2060-3.

18. Martineau AR, Wilkinson KA, Newton SM, Floto RA, Norman AW, SkolimowskaK, et al. IFN-gamma- and TNF- independent Vitamin D-inducible human suppression of mycobacteria: the role of cathelicidin LL-37. J Immunol2007; 178:7190-98.

19. Liu PT, StengerS, Li H, Wenzel L, Tan BH, KrutzikSR, etal.2 Tolllike receptor triggering of a Vitamin D: mediated human antimicrobial response. Science 2006; 311:1770-3.

20. Davies PD, Brown RC, WoodheadJS. Serum concentrations of vitamin D metabolites in untreated tuberculosis. Thorax 1985; 40:187-90.

21. Sachan A, Gupta R, Das V, Agarwal A, Awasthi PK, Bhatia V. High prevalence of vitamin D deficiency among pregnant women and theirnewbornsinNorthernIndia.AmJClinNutr2005;81:1060-4.

22. Puri S, Marwaha RK, Agarwal N, Tandon N, Agarwal R, Grewal K, et al. Vitamin D status of apparently healthy schoolgirls from two different socioeconomic strata in Delhi: Relation to nutrition and lifestyle. Br J Nutr2008;99:876-82.

23. Arya V, Bhambri R, Godbole MM, Mithal A. Vitamin D status and 
its relationship with bone mineral density in healthy Asian Indians. Osteoporos Int2004;15:56-61.

24. HarinarayanCV, RamalakshmiT, Prasad UV, SudhakarD, SrinivasaraoPV, SarmaKV, et al. High prevalence of low dietary calcium, high phytate consumption, and vitamin D deficiency in healthy South Indians. Am J ClinNutr2007;85:1062-7.

25. HarinarayanCV. Prevalence of vitamin Dinsufficiencyin postmenopausal South Indian women. OsteoporosInt, 2005; 16:397-402.

26. Martineau AR, Wilkinson RJ, Wilkinson KA, Newton SM,
Kampmann B, Hall BM, et al. A single dose of vitamin D enhances immunity to mycobacteria. Am J Respir Crit Care Med 2007;176:208-13.

27. Jeon CY, Murray MB. Diabetes mellitus increases the risk of active tuberculosis: A systematic review of 13 observational studies.PLoSMed 2008;5:e152.

28. Restrepo BI. Convergence of the tuberculosis and diabetes epidemics: Renewal of old acquaintances. Clin Infect Dis 2007;45:436-8.

Copyright: () the author(s), 2020. It is an open-access article distributed under the terms of the Creative Commons Attribution License (CC BY 4.0), which permits authors to retain ownership of the copyright for their content, and allow anyone to download, reuse, reprint, modify, distribute and/or copy the content as long as the original authors and source are cited.

How to cite this article: Jain SK. Analysis of Serum 25- $(\mathrm{OH})$ D Levels status in Subjects Suffering from Pulmonary Tuberculosis: A Teaching Hospital Based study in Western Uttar Pradesh Region. Asian J. Med. Res. 2020;9(1):PM01-PM04.

DOI: dx.doi.org/10.47009/ajmr.2020.9.1.PM1

Source of Support: Nil, Conflict of Interest: None declared. 